\title{
Tissue quality of formalin adulterated nile tilapia Oreochromis Niloticus fish: A histopathological perspective
}

\author{
S. M. Nomanuzzaman', M. N. Nasera, M. Begum ${ }^{\text {b }}$, A. T. M. Abdullah ${ }^{\text {, }}$ T. A. Khan ${ }^{\text {b }}$ \\ M. M. Rahman ${ }^{b}$ and N. Khan*b \\ ${ }^{a}$ Department of Zoology, University of Dhaka \\ ${ }^{b}$ Institute of Food Science and Technology (IFST), BCSIR, Dhaka-1205, Bangladesh
}

\begin{abstract}
In view of recent adulteration of fish in retail markets with formalin, a mock-up effort was made at laboratory condition to assess the tissue quality of formalin contaminated fish. Tilapia fish samples were intentionally despoiled with $1 \%$ formalin for 1 hour and kept exposed in open shelves for spoilage. Fish tissue quality was histopathologically tested at 0, 6, 12, 16, 20 and 24 hours intervals. From the histopathological perspective the tissue quality were found to be deteriorating gradually with time. The rate of desolation of tissue was maximum after 20 hours of sampling. The fresh ( 0 hour) muscle sample was found to be fairly intact. Observation of the fish samples at 6, 12 and 16 hours showed minimum degradation of muscle tissue within acceptable level. One hour exposure to $1 \%$ formalin was not found sufficient to prevent deterioration and preserve fish muscle for longer period. But this concentration of formalin and the exposure time retained the tissue quality and delayed desolation of muscle tissue for 15 to 16 hours.
\end{abstract}

Keywords: Fish adulteration; Formalin; Histopathological study; Deterioration; Photomicrography.

\section{Introduction}

Fish is a highly perishable commodity and the most available source of protein for Bangladeshi population. From recent media reports it is evident that, dishonest fish traders use formalin to prevent spoilage and decomposition of fish. As a strong fixative, formalin was supposed to fix fish muscle tissue by reacting with protein and prevents decomposition (Humason, 1972). The most frequent type of cross-link formed by formaldehyde in collagen is between the nitrogen atom of a peptide linkage, and the number of such crosslinks increases with time (Gustavoson, 1956). Formalin or formaldehyde prevents decomposition of tissue as the digestive tissue of decomposers (bacteria, fungi) cannot fit themselves on to these newly formed compounds.

Formalin has many fold use in animal tissue preservation. However the application of formalin in this case is very high and the fish is unacceptable for consumption. Although the fish adulterer traders do use lower concentration of formalin, no high logical assay was evident literally. Information received from some sources about the quantity of formalin mixed with water to adulterate fish was estimated and it was assumed that the concentration of formalin was near about $1 \%$. The present approach was made to support *Corresponding author. E-mail: nkhan_bcsir@yahoo.com the objectives for determination of the histopathological changes with time and strength of $1 \%$ formalin to prevent fish muscle decomposition. After treating freshly caught tilapia (Oreochromis niloticus) with 1\% formalin for 1 hour the samples were studied for histopathological changes at different time intervals.

\section{Materials and methods}

Fresh tilapia fish was caught from a private fish farm at Dhaka Cantonment. Collected fish samples were immediately taken to the laboratory in ample of ice for the simulation experiment. A group of fish were treated with $1 \%$ formalin for 1 hour and kept exposed in open air. After treating with formalin, muscle samples were collected from dorsal side of the fishes at 0 hour, 6 hour, 12 hour, 16 hour, 20 hour and 24 hour observation for histopahthological test. Fresh fish was tested as control. Fish samples were analyzed in the laboratory from August 2006 to July 2007.

\section{Histopathological Investigation}

Permanent slides were prepared following the methods (Culling, 1957, Naser and Farhana, 2005 and Naser and 
Mustafa, 2006) modified from (Humason, 1972). From each adulterated and non-adulterated tilapia fish one thin slice of muscle up to $5 \mathrm{~mm}$ thick was taken from dorsal side.

\section{Preparation of permanent histological slide}

\section{Fixation of tissue sample}

The sampled muscle tissues were quickly washed with physiological saline solution $(0.9 \% \mathrm{w} / \mathrm{v}$ of $\mathrm{NaCl})$ after dissection and fixed in Buins fluid (Hopwood, 1969). Just between 8 and 18 hours the samples were washed with physiological solution and $70 \%$ ethanol. The samples were preserved in separate vials in $70 \%$ alcohol marked with date, sample number and time until further processed.

\section{Processing of tissue}

\section{a. Dehydration}

The fixed tissues were gradually dehydrated in ascending concentration of alcohol (ethanol) from $70 \%$ (10 minutes) to $80 \%$ (20 minutes) and absolute alcohol (20 minutes).

\section{b. Clearing}

After dehydration the tissues were cleared in Xylene. If it appears white, the tissue was again poured back into absolute ethanol for additional 15 minutes.

\section{c. Paraffin impregnation}

A paraffin bath with temperature range $60^{\circ}-70^{\prime} \mathrm{C}$ was used. The melting point of paraffin was $58^{\circ}-62^{\circ} \mathrm{C}$. The tissue was treated in xylene-paraffin (30 minutes) followed by moltenparaffin 1 hour (Walter 1980).

\section{d. Paraffin embedding:}

Embedding in melted paraffin was done immediately after molted-paraffin treatment step. Precaution was made for not using boiled paraffin (temperature over $60^{\circ} \mathrm{C}$ ) to avoid tissue rousting.

\section{e. Block making:}

Paraffin dispenser was used for block making. Molten paraffin was then poured onto a iron blocked plate. The tissue was carefully embedded in a paper plane. The blocked plate was allowed to harden in the ice chamber of a refrigerator.

\section{f. Trimming}

The blocks were then trimmed properly to the size of the tissue by cutting off the extra paraffin and were kept in the ice chamber for sometime before cutting the section.

\section{g. Section cutting}

The block was fitted to the microtome for sectioning. A sharpened microtome knife was used for cutting sections. The temperature of the water bath was maintained between $45^{\circ}-50^{\circ} \mathrm{C}$ for stretching the ribbon on it. Sections were cut at 4-5 micron in thickness.

\section{h. Affixing}

The ribbon of tissue was attached on the slide by means of Mayer's albumen (Fresh egg white $50 \mathrm{~m} 1$, Glycerin $50 \mathrm{~m} 1$ and Sodium Salicylate $5 \mathrm{ml}$ mixed in $20 \mathrm{ml}$ distilled water). 3-5 drop of Mayer's albumen was put in one side of a slide (Pearse, 1980). The ribbon of the tissue was arranged in rows onto the slides. The slides were then kept in standing position for sometime to drain out the water and finally allowed to dry at $25^{\circ}-34^{\circ} \mathrm{C}$ in warm oven.

\section{i. Deparaffinization}

The slides with ribbons containing tissue were kept in the warmer for melting at $60^{\circ} \mathrm{C}$ for ten minutes. This was followed by immersing the slides in xylene for ten minutes to remove the wax.

\section{j. Re-hydration of tissue}

The slides with section of tissue were gradually re-hydrated in descending concentration of ethyl alcohol from absolute alcohol, $80 \%, 70 \%$ and $50 \%$ keeping ten minutes in each. At the end of this process tap water was used to remove the alcohol residue (Lillie, R.D. 1947).

\section{k. Staining}

For staining the following steps were followed (Baker, J.R. 1958):

Dipped in Haematoxylene- 5 minutes washed properly with running water

Dipped in $0.5 \%$ alcohol-15 second, washed again with running water.

Dipped in Ammonia- 1 minute washed with running water.

Dipped in Eosin- 01 to 02 minutes

\section{l. Dehydration}

The slides were then dehydrated gradually with alcohol in the following ways: Alcohol- $70 \%$ for 5 minutes Alcohol$90 \%$ for 3-5 minutes Alcohol- $100 \%$ for 15 minutes.

\section{m. Cleaning}

The stained tissues were cleaned in Xylene-I, Xylene-I I, and Xylene- III for two minutes each. 


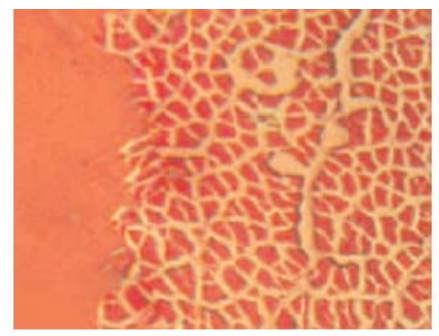

Plate 1. T S of control (firesh) fish musde at 0 hour

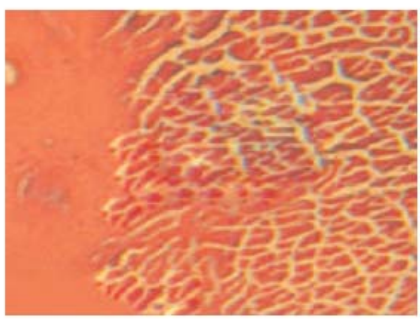

P1ate 2. T S of 1\% formalin

adulterated fish musde at 0 hour

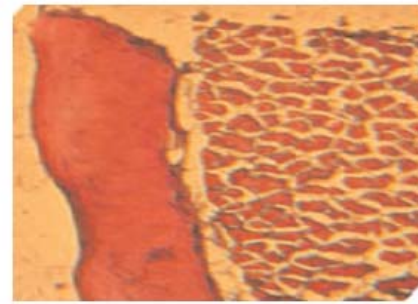

Plate 4. T S of $1 \%$ formalin

adulterated fish musde at 12 hours

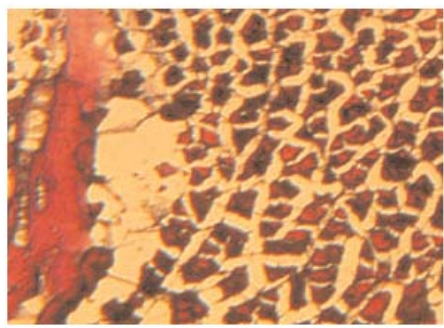

Plate 6. T S of $1 \%$ formalin adulterated fish musde at 20 hours

n. Mounting

After cleaning, permanent mounting of the slides was made by using Canada balsam.

\section{o. Labeling}

Finally the slides were labeled according to the samples. The slides were then ready for observing under compound micro-

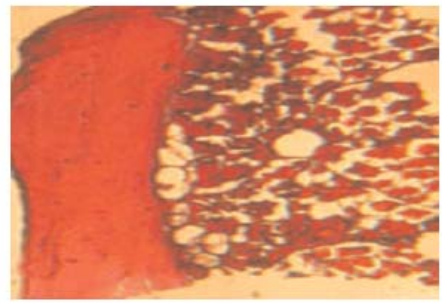

P1ate 3. T S of $1 \%$ formalin

adulterated fsh musde after 6 hours

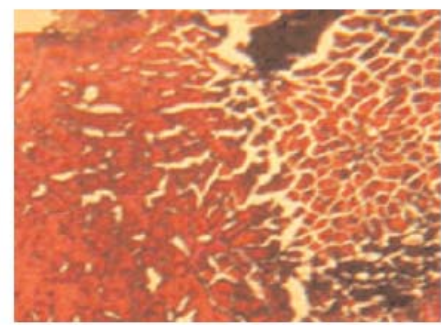

P1ate 5. T S of 1\% formalin adulterated fish muscle at 16 hour

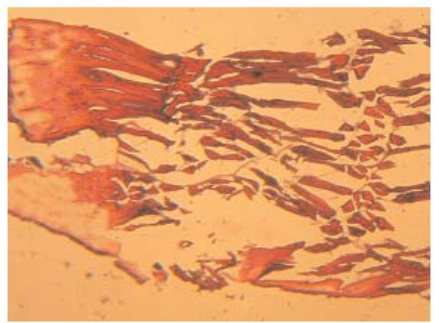

P1ate7. T S of 1\% formalin

adulterated fish musde at 24 hours

scope and photomicrograph.

Photomicrography

The photomicrographs were taken by using a digital microscopic camera. Micrographs of desired muscle tissues were taken at different magnifications using eye piece 10 and objectives $3.5,10$ or 20 as was observed. 


\section{Results and discussion}

Histopathological changes in muscles of $1 \%$ formalin adulterated tilapia fish

Histopathological slides demonstrate that the formalin adulterated muscle tissue at 0 hour is almost similar to that of control sample in appearance (Plate $1 \& 2$ ). No remarkable visible quality changes occurred in the tissue sample at the beginning of the experiment. Muscles looked fresh and no visible physical changes took place. The muscle fibers appeared in intact condition. The peripheral and inner muscle fibers did not differ with respect of their interrupted sequences in the muscle fibers in both control and 0 hour formalin adulterated tissue sample.

The samples observed after 6 hour, 12 hour, 16 hour, 20 hour and 24 hour showed changes in tissue structure of musculature (Plate 3 to 7). Gradual degradation was observed in the consecutive slides. Slight decrease of the organoleptic characteristics was noticed in the muscle sample after 6 hours of exposure to air (Plate 3). The rate of desolation was increased at later stages of observation (Plate 4 to 7). Apparently, the muscle tissue quality was found to be in acceptable condition even after 16 hours exposure to open air (Plate 5).

Unfavorable changes were observed in the muscle fibers of 20 hour and 24 hour samples (Plates 6 and 7). Desolation and destruction of membrane was visible. The myofibril bundles were irregular, loosely attached with huge extra cellular space. Water binding capacity of the muscle was lower than all the other muscles observed in the experiment. The histopathological study clearly shows the gradual spoilage of the fish muscles in 24 hours time.

\section{Conclusion}

From the above observation, it can be concluded that exposure to $1 \%$ formalin for 1 hour was not effective to prevent muscle decomposition and preserve fish muscle for longer than 20 hours period when exposed to open air. In fish market fish traders possibly preserve the fishes in relatively higher concentration of formalin for longer period to preserve fish for several hours without ice. Although the present study revealed that the tested concentration of formalin delayed desolation of muscle tissue for 15 to 16 hours, in concern to the health hazard effect it should be avoided to use in fish.

\section{References}

Baker JR (1958), Principles of biological Microtechnique (Reprinted 1970, with corrections). London, Methuen.

Culling CFA (1957), Handbook of Histopathological Technique. London, Butterworths.

Gustavson KH (1956), The Chemistry of Tanning Processes. New York: Academic Press.

Hopwood D (1969), Fixative and Fixation: a review. Histochemical Journal 1: 323-360.

Humason GL (1979), Animal Tissue Technique. W.H. Freeman and Company, San Francisco.641 pp.

Lillie RD (1947), Histological Technique and Histochemistry. New York; McGraw-Hill Books Company.

Naser MN and Farhana Z (2005), Some histological and histomorphic aspects of the digestive system of the Rui fish, Labeo rohita (Hamilton, 1822) from Bangladesh., Bangladesh J. Zool., 33(1): 1-8.

Naser MN and Mustafa T (2006), Histological and histomorphometric aspects of the digestive system of the taki fish, Channa punctatus (Bloch-Schneider, 1801). Bangladesh J. Zool. 34(2): 205- 212.

Pearse AGE (1980), Histochemistry, Theoritical and Applied, 4th edn. Vol.1.

Walter F (1980). The microtome manual of the technique of preparation and of section cutting. Germany; Ernst Leitz Wetzlar GMBH.

Received: 29 March 2012; Revised: 03 July 2012; Accepted:23 August 2012 . 